\title{
Dynamic Mechanical, Dielectrical, and Rheological Analysis of Polyethylene Terephthalate/Carbon Nanotube Nanocomposites Prepared by Melt Processing
}

\author{
Juris Bitenieks $\mathbb{D}^{1},{ }^{1}$ Remo Merijs Meri, ${ }^{1}$ Janis Zicans, ${ }^{1}$ and Krisjanis Buks ${ }^{2}$ \\ ${ }^{1}$ Institute of Polymer Materials, Faculty of Materials Science and Applied Chemistry, Riga Technical University, Latvia \\ ${ }^{2}$ Institute of Chemical Physics, University of Latvia, Latvia \\ Correspondence should be addressed to Juris Bitenieks; juris.bitenieks@rtu.lv
}

Received 26 February 2020; Revised 17 April 2020; Accepted 22 April 2020; Published 9 May 2020

Academic Editor: Domenico Acierno

Copyright ( 2020 Juris Bitenieks et al. This is an open access article distributed under the Creative Commons Attribution License, which permits unrestricted use, distribution, and reproduction in any medium, provided the original work is properly cited.

\begin{abstract}
The polyethylene terephthalate/carbon nanotube (PET/CNT) nanocomposites were prepared by melt mixing using a twin screw extruder. CNT content was varied up to $5 \mathrm{wt}$. \%. Morphology as well as dynamic mechanical, calorimetric, and rheological properties of the PET/CNT nanocomposites was investigated. Morphological studies indicated that CNT bundles are regularly distributed within the polymer matrix creating a connected network structure which significantly affects the nanocomposite properties. Dynamic mechanical thermal analysis revealed increase in storage and loss modules of the investigated PET nanocomposites by increasing the content of CNTs. Differential scanning calorimetry results demonstrated increase in crystallinity of the investigated PET nanocomposites upon addition of the nanofiller. Rheological studies demonstrated that CNT addition up to $5 \mathrm{wt}$. \% caused increment in complex viscosity and storage modulus. Rheological percolation threshold was observed to be $0.83 \mathrm{wt}$. \% of CNT concentration, respectively.
\end{abstract}

\section{Introduction}

During the last decades, polymer nanocomposites have attracted attention as a class of advanced composite materials with a wide range of mechanical, electrical, and rheological properties making them useful in multifunctional applications. Improvement of functional properties of polymer nanocomposites is due to both intrinsic properties of nanoscale fillers and desirable pattern of matrix-filler and fillerfiller interactions during the manufacturing stage.

Since their relatively recent discovery, carbon nanotubes (CNTs) have found many useful applications due to their unique intrinsic properties, including structural features like high aspect ratio and flexibility, exceptionally high stiffness and strength, and uncommon structure-dependent electrical and thermal conductivity characteristics. Use of CNTs as reinforcement for CNT-based polymer composites has emerged in the past years due to their ability to simultaneously enhance mechanical, electrical, and thermal properties of polymer matrix. As described in previous works $[1,2]$,
CNTs dispersed in many thermoplastic polymer matrices are capable of forming connected networks at low filler concentration which is beneficial from the processing and cost perspective at the same time acquiring benefits of modified physical properties.

One of the most versatile polymer matrices for CNTfilled polymer nanocomposites is polyethylene terephthalate (PET). PET is an engineering thermoplastic polymer that exhibits excellent mechanical properties [3]. PET is supplied in a variety of different forms, including fiber, film, and granulate, used for manufacturing of neat or composite products for global economics including textile, packaging, electrical and electronics, automotive, and construction markets. PET nanocomposites have been developed by a broad range of manufacturing routes. Consequently, PET has been used as a substrate to create single- or multilayered nanostructures using a variety of coating/deposition/layer transfer techniques (e.g., R2R technique as demonstrated by Abbel et al. [4]). Concomitant fiber-forming properties of PET have been utilized to form nanocomposite fibers (e.g., 
electrospinning [5]). Besides it, PET has been also used as a matrix of bulk nanocomposites obtained by means of a number of manufacturing techniques (e.g., in situ polymerization, solvent-based, solid-state, and thermoplastic processing techniques [2]). In the latter case, melt processing of PET with PET/CNT masterbatch offers an advantage of using a simple and commercially attractive manufacturing method that allows to achieve reasonable CNT dispersion in PET matrix at low CNT concentrations.

Properties of melt processed PET nanocomposites with carbonaceous nanofillers are found to greatly depend on the various structural factors such as nanofiller type as reported by Xin et al. [6], functionalization as demonstrated by Yesil and Bayram [7], and especially dispersion degree within the polymer matrix as shown by Alig et al. [8] and Du et al. [9]. Thus, Rodríguez-Uicab et al. [10] investigated the influence of tailoring of a melt processing method for PET/CNT nanocomposite manufacturing by combining direct extrusion either with premelt compounding or ultrasound-assisted solvent-based premanufacturing approach. It was concluded that mixing the CNT by melt compounding before extruding yields better dispersion of the MWCNTs within the PET matrix, while the processing method assisted by a solvent resulted in matrix plasticization [10]. Although generally virgin PET has been considered a matrix for bulk nanocomposites with carbonaceous fillers, in some cases, recycled PET has been also used. Thus, Chowreddy et al. [11] have used the masterbatch approach to obtain recycled PET nanocomposites with improved processability and performance. Due to improved dispersion of carbonaceous nanofillers within the PET matrix, increment of mechanical, barrier, electrical, and other exploitation properties can be achieved at lower nanofiller content in comparison to traditional microcomposites thus contributing to cost reduction. By considering that commercially the main aim is reduction of the effective CNT content, the concentration of carbonaceous nanofillers within melt-processed PET matrix composites usually is not higher than $10 \mathrm{wt}$. \%. At the moment, in the published investigations, the effects of CNT addition on the structure as well as electrical, mechani$\mathrm{cal}$, and thermal properties of melt compounded PET nanocomposites have been mainly revealed. For an example, Rodríguez-Uicab et al. [10] have demonstrated that a CNT filler acts as a nucleating agent within the PET matrix; however, the authors have not observed any considerable shift in glass transition temperature, which could denote the stiffening effect of polymer macromolecules by CNT. Although, Chowreddy et al. [11] have observed certain increase of glass transition temperature of the PET nanocomposite with CNT; the increment was rather small. Disregarding this small influence, many authors, including [7, 10, 12, 13], have observed improvement in mechanical properties, mainly modulus of elasticity and strength, along with increasing CNT content within the PET matrix. A positive effect of CNT addition has been observed also with respect to increased thermal stability of PET/CNT nanocomposites, as demonstrated by Alshammari and Wilkinson, for an example [13]. Considerable improvement has been observed also in electrical conductivity with increasing CNT content within the PET matrix. Thus, several author groups have stated values of electrical percolation threshold as low as $0.05-0.33$ wt. \% $[13,14]$. In spite of these positive effects, addition of a CNT filler to the PET matrix usually has resulted in decreased flexibility and limited processability of the nanocomposites. With respect to limited processability, rheological percolation threshold can be stated. As demonstrated by a number of authors, rheological percolation threshold may be lower than electrical percolation threshold due to the fact that a less dense CNT network is required to sufficiently impede chain mobility related to the rheological percolation threshold [15]. By considering these results, melt-manufactured PET nanocomposites have a potential to be applied as extruded, injection-molded, or compressionmolded products in smart applications simultaneously requiring high mechanical resistance, thermal stability, and electrical conductivity. In this aspect, thermoelectric performance of composite materials has become increasingly attractive, especially in the light of increased energy demand, on the one hand, and reduced availability on energy supply due to diminishing amount of fossil resources, on the other hand. There are almost no investigations with respect to thermoelectric characterization of melt-manufactured PET nanocomposites with CNT. In our recent manuscript [16], we have demonstrated that addition of CNTs to the PET matrix via melt extrusion allows to obtain materials with a certain thermoelectric effect. Consequently, in this research, the idea on manufacturing of thermoelectric materials based on PET/CNT nanocomposites is extended by paying greater attention to rheological property characterization of the nanocomposites in conjunction with assessment of structural, mechanical, and electrical properties.

Particularly, in this study, attention was paid to describe simultaneous influence of CNTs on morphological, calorimetric, mechanical, dielectric, and rheological properties of the said nanocomposites. Conventional melt processing by using a twin screw extruder was applied to dilute commercial PET/CNT masterbatch with the PET matrix. The following measurement techniques were used to reveal the influence of CNT nanofiller on the performance of PET matrix nanocomposites: dynamic mechanical thermal analysis was performed to study the mechanical behavior over a broad temperature range, oscillatory rheometry measurements were applied to investigate rheological properties over a broad angular frequency range, broadband dielectric spectroscopy analysis was performed to reveal the dielectric behavior over a broad frequency range, scanning electron microscopy was used to reveal morphological characteristics, and differential scanning calorimetry analysis was used to determine the crystallization behavior.

\section{Materials and Methods}

2.1. Materials. As a matrix material, PET Lighter C93, supplied from Equipolymers, was used. The density of PET was $1.342 \mathrm{~g} / \mathrm{cm}^{3}$; melt flow index at $260^{\circ} \mathrm{C}$ and $2.16 \mathrm{~kg}$ was $36.5 \mathrm{~g} / 10 \mathrm{~min}$; tensile strength was $24 \mathrm{MPa}$, and tensile modulus was $2300 \mathrm{MPa}$. As a filler material, commercial PET/CNT masterbatch from Hyperion Catalysis International was used. The masterbatch consisted of $15 \mathrm{wt}$. \% FIBRIL multiwalled CNT dispersion in PET, and its melting 


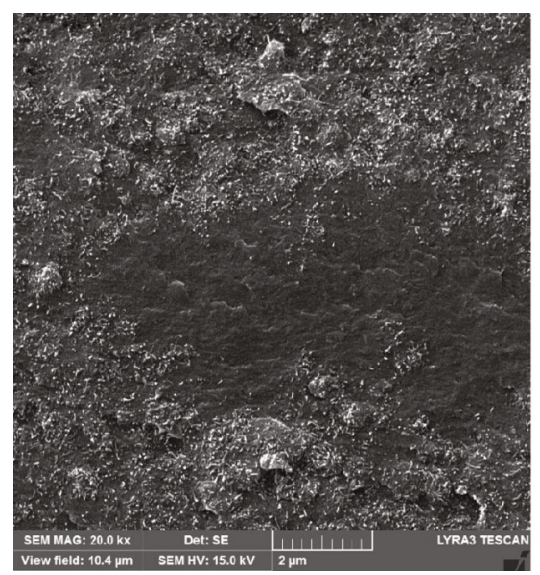

(a)

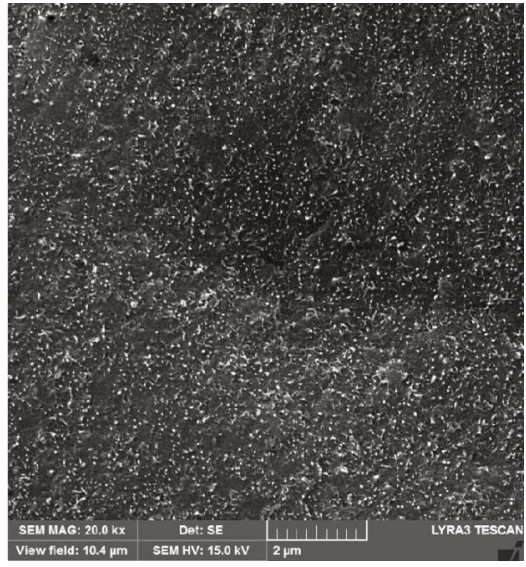

(b)

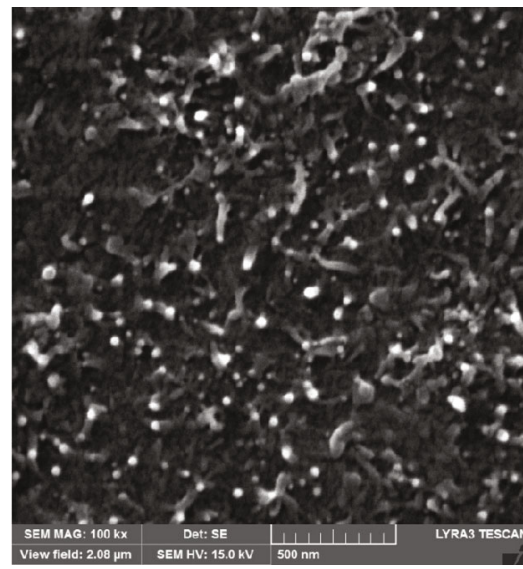

(c)

Figure 1: SEM images of PET/CNT masterbatch (a) and the nanocomposite with $5 \mathrm{wt}$ \% CNT content (b, c).

temperature was $250^{\circ} \mathrm{C}$. The average outer diameter of FIBRIL CNTs is approximately $10 \mathrm{~nm}$ and has an average length over $10 \mu \mathrm{m}$.

2.2. Preparation of the PET/CNT Nanocomposites. The PET/CNT nanocomposites were obtained by using corotating twin screw extruder PRISM TSE 16 TC; PET/CNT masterbatch was diluted with PET to obtain the nanocomposites with various CNT weight contents not exceeding $5 \mathrm{wt}$. \%. Prior to melt processing, the materials were dried at $170^{\circ} \mathrm{C}$ for $4 \mathrm{~h}$. The extruder barrel temperatures from the feeding zone to the head zone were maintained between 240 and $270^{\circ} \mathrm{C}$. The extruded material was cooled in a water bath and granulated. To minimize the effects of flow orientation, obtained PET/CNT nanocomposites were compression molded into $1 \mathrm{~mm}$ thick sheets by using hydraulic press Carver $\mathrm{CH} 4386$ at $270^{\circ} \mathrm{C}$ and $3 \mathrm{MPa}$ pressure. Samples for further experiments were cut out from the compressionmolded sheets.

2.3. Characterization. Morphology of PET/CNT nanocomposites was observed by using scanning electron microscope (SEM) Tescan Lyra3 XM operated at $15 \mathrm{kV}$ accelerated voltage. The specimens were fractured in liquid nitrogen and covered with a layer of gold.

Dynamic mechanical thermal properties of the obtained PET/CNT nanocomposites were determined according to EN ISO 6721-2 in tensile mode. Storage modulus $\left(E^{\prime}\right)$ and loss modulus $\left(E^{\prime \prime}\right)$ were measured by using dynamic mechanical thermal analyzer Mettler Toledo DMA/SDTA861. Experiments were performed in the temperature range from $+20^{\circ} \mathrm{C}$ to $+150^{\circ} \mathrm{C}$ at $1 \mathrm{~Hz}$ frequency.

Differential scanning calorimetry (DSC) measurements were carried out by using Mettler Toledo DSC 1/200 W equipment. Experiments were performed in nitrogen atmosphere within temperature scans from $+25^{\circ} \mathrm{C}$ to $+300^{\circ} \mathrm{C}$ at a heating rate of $10^{\circ} \mathrm{C} / \mathrm{min}$.

Dielectric spectroscopy measurements were carried out at room temperature by means of a Novocontrol Concept 50 Broadband Dielectric Spectroscopy analyzer. Dielectric permittivity $\left(\varepsilon^{\prime}\right)$ was determined in a wide frequency range from $10^{-2}$ to $10^{7} \mathrm{~Hz}$.

Rheological measurements were performed by using rotational rheometer REOLOGICA StressTech NOVA equipped with $25 \mathrm{~mm}$ parallel plate geometries. Gap width was set to $1 \mathrm{~mm}$, and measurement temperature was $270^{\circ} \mathrm{C}$. The strain values were chosen in order to be within the linear viscoelastic region. Complex viscosity $\left(\eta^{*}\right)$ and storage modulus $\left(G^{\prime}\right)$ of the melt were measured in oscillatory mode over the angular frequency range of 4 decades.

\section{Results and Discussion}

3.1. Morphological Characterization. A SEM image of raw PET/CNT masterbatch (Figure 1(a)) with 15 wt. \% CNT content reveals a structure with uneven CNT distribution in the PET matrix although in situ polymerization method was used for this masterbatch manufacturing. However, the morphology of PET/CNT nanocomposite containing $5 \mathrm{wt}$. \% of the nanofiller (Figure 1(b)) shows that CNTs can be homogeneously dispersed and distributed within the polymer matrix without any signs of noticeable agglomeration by using melt processing with a twin screw extruder where under the influence of shear forces during processing, CNTs are effectively distributed in a whole polymer matrix volume. Greater magnification (Figure 1(c)) shows uniform CNT dispersion in the polymer matrix with distinctive CNT bundles with reasonable adhesion between the polymer matrix and nanofiller. These twisted CNT bundles provide reinforcement for the polymer matrix which also plays an important role in dielectric and rheological properties and such other properties as electrical and thermal conductivity.

3.2. Dynamic Mechanical and Calorimetric Properties. Storage modulus temperature relationships $E^{\prime}(T)$ of PET/CNT nanocomposites (Figure 2(a)) reveal a complex elasticity behavior of the nanocomposites over the investigated temperature range. Below the glass transition region, almost linear 1.2-fold increment of $E^{\prime}$ is observed by increasing CNT content up to $5 \mathrm{wt}$. \%, indicating a CNT reinforcing effect. As expected, within the glass transition region, a rapid drop 


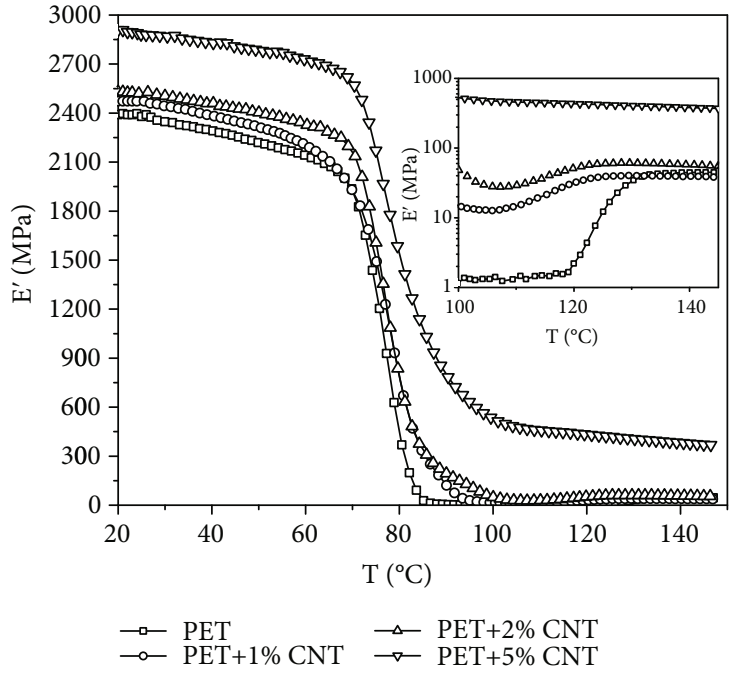

(a)

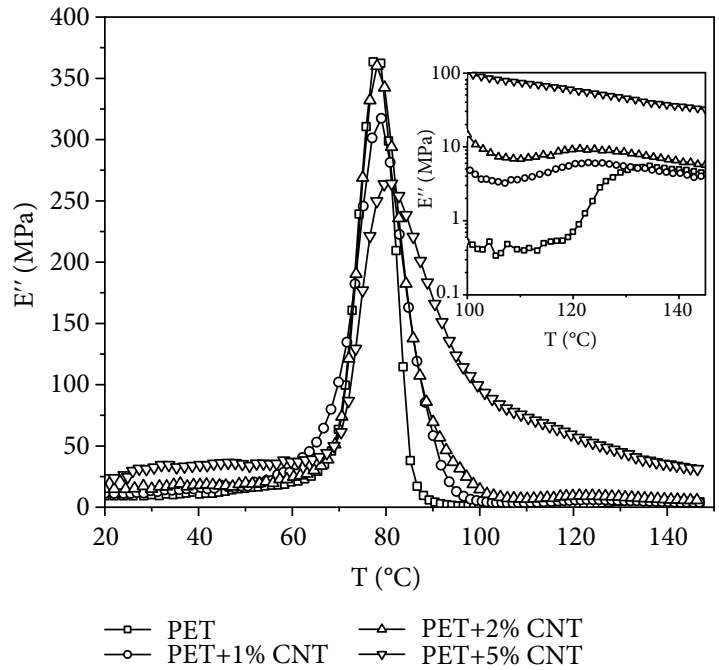

(b)

FIGURE 2: PET/CNT nanocomposite storage modulus $E^{\prime}$ (a) and loss modulus $E^{\prime \prime}$ (b) depending on the temperature.

of the modulus values for a neat PET matrix and the investigated nanocomposites is observed by rising temperature; however, a broader glass transition region is observed in the case of the systems with CNTs, especially at the highest nanofiller content, denoting that CNTs considerably affect the glass transition behavior of the polymer. In the meantime, evident increment in glass transition temperature $\left(T_{\mathrm{g}}\right)$ of the investigated PET/CNT nanocomposite is observed by increasing the nanofiller content. Although, immediately above glass transition, a rapid drop of $E^{\prime}$ has been observed, considerable reinforcing effect of CNTs is maintained; at ca. $105^{\circ} \mathrm{C}, E^{\prime}$ is increased 8,18 , and more than 300 times by increasing the nanofiller content to $1 \mathrm{wt}$. \%, $2 \mathrm{wt}$. \%, and 5 wt. \%, respectively. At higher temperatures above glass transition of PET, a certain $E^{\prime}$ increment occurs. Evidently, this stiffness increase is associated with cold crystallization phenomena in PET. Thus, for the neat polymer matrix or at the CNT content in the nanocomposite below 2 wt. \%, the rate of cooling during manufacturing is higher than the rate of crystallization of PET macromolecules, leading to frozen conformations, which are being able to add crystallization if certain trigger temperature is achieved.

It is interesting to note that cold crystallization-initiated stiffness increase is shifted towards the direction of lower temperatures along with increasing CNT content; furthermore, the increment of $E^{\prime}$ is decreased along with increasing the concentration of CNTs. Thus, at the highest nanofiller content above the $T_{\mathrm{g}}$ region, no modulus increase is observed at all; $E^{\prime}(T)$ relationship of PET $+5 \%$ CNT nanocomposite represents smooth inverse sigmoidal mode with the modulus values greater than any other composition of the investigated nanocomposite. This is consistent with the DSC data (Figure 3) demonstrating a considerable decrement of cold crystallization peak area from $21.59 \mathrm{~J} / \mathrm{g}$ (neat PET) to $0.75 \mathrm{~J} / \mathrm{g}$ (the PET nanocomposite with $5 \mathrm{wt}$. \% CNTs) and the corresponding decre-

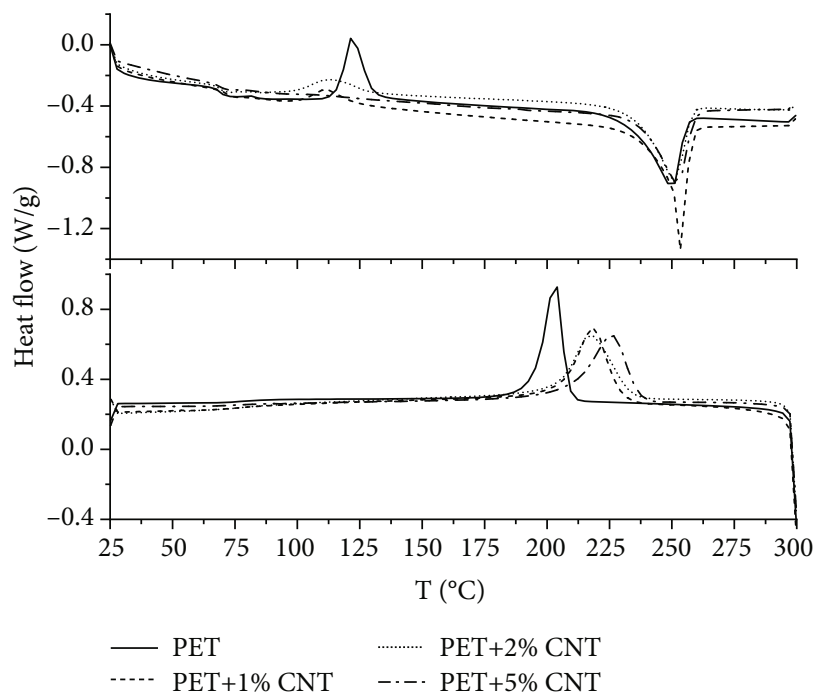

FIgURE 3: PET/CNT nanocomposite DSC heating and cooling curves.

ment of cold crystallization peak temperature from ca. $122^{\circ} \mathrm{C}$ to $108^{\circ} \mathrm{C}$ yielding to an increment of initial crystallinity of the nanocomposites from $13 \%$ (neat PET) to $31 \%$ (the nanocomposite with $5 \mathrm{wt}$. \% CNTs).

Such a phenomenon could denote the fact that crystallization of the nanocomposites from the melt is promoted by the presence of CNTs leading to higher initial crystallinity of the nanocomposite. Consequently, during the heating stage within the DSC experiment, the capacity of cold crystallization, i.e., crystallization of the frozen macromolecular conformations, decreases along with growing CNT content. However, independently from the CNT content, cold crystallization-induced modulus increase of the investigated nanocomposites is not greater than $30-40 \mathrm{MPa}$. Notwithstanding the cold crystallization-caused modulus increase 


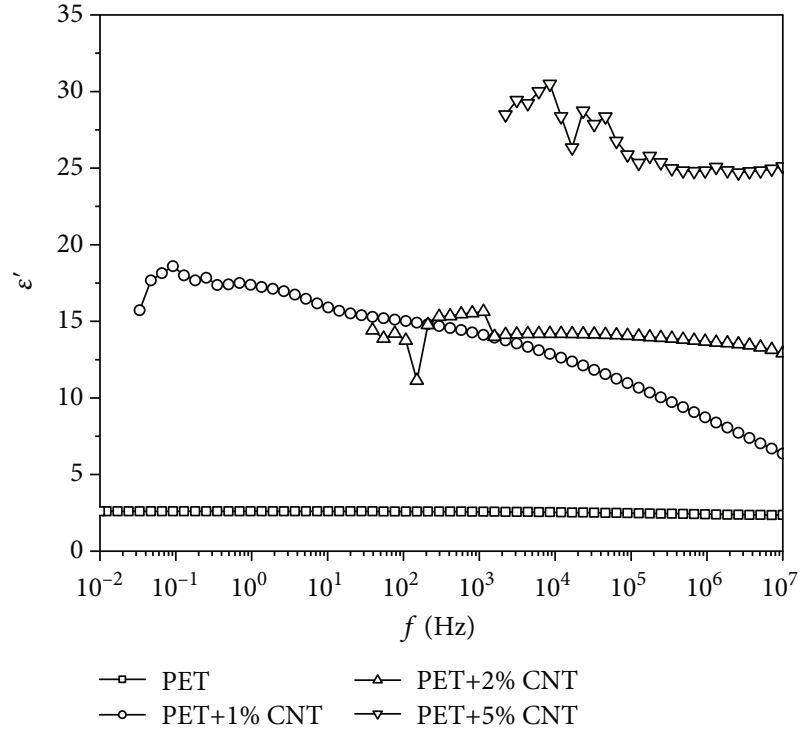

FIgURE 4: PET/CNT nanocomposite dielectric permittivity $\varepsilon^{\prime}$.

above $T_{\mathrm{g}}$ of the investigated PET-based nanocomposites in the measured temperature range depend on the CNT content, if in the case of the PET matrix, increased modulus values are maintained over the whole temperature interval investigated, then in the case of the PET nanocomposites, modulus values are starting to decrease soon after reaching maximum at $\mathrm{ca} .120^{\circ} \mathrm{C}$. The reason for such phenomena could be lower interfacial adhesion in the systems with CNTs.

PET/CNT nanocomposite loss modulus $E^{\prime \prime}$ (Figure 2(b)) represents the damping behavior, which denotes the polymer's ability to disperse mechanical energy through internal molecular motion. Decreased $E^{\prime \prime}(T)$ peak height and the respective peak area of the system with $5 \mathrm{wt}$. \% of CNT (with respect to neat PET) around the glass transition region $\left(60-90^{\circ} \mathrm{C}\right)$ indicate a lower damping behavior of the nanocomposite due to reduced mobility of polymer macromolecules, leading to certain increment of $T_{\mathrm{g}}$ of PET. It is, however, interesting to note that at higher temperatures, the behavior is reverse, i.e., better damping is demonstrated by the nanocomposites, which could be related to improved performance of the nanocomposites at elevated temperatures. The observed increment in $T_{\mathrm{g}}$ due to reduced macromolecular chain mobility correlates well with increased $E^{\prime}$ as demonstrated above.

3.3. Dielectric Properties. As a typical dielectric material, the PET matrix shows frequency-independent experimentally measured dielectric permittivity $\varepsilon^{\prime}$ value of 2.6 (Figure 4 ). However, for measured PET/CNT nanocomposites, increased $\varepsilon^{\prime}$ values are observed that occur due to interphase polarization between conducting CNTs and insulating PET matrix. The reason for this effect is the high conductivity difference between these two materials that determines when current is flowing through the interphase; electric charges are accumulating in the interphase resulting in significant

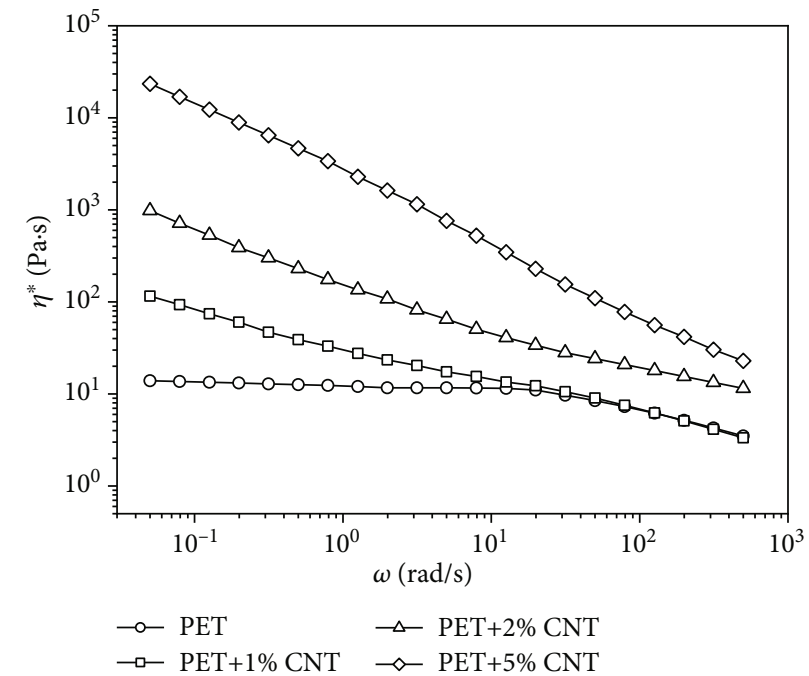

FIgURE 5: PET/CNT nanocomposite complex viscosity $\eta^{*}(\omega)$ curves.

dielectric permittivity $\varepsilon^{\prime}$ increase [17]. In the PET/CNT nanocomposite case, this means that CNTs are separated from each other with a thin dielectric PET layer; as a result, between contiguous CNTs, parallel plate capacitors are formed. By increasing the CNT concentration, the amount of capacitors increases; however, at the same time, the distance between CNTs decreases as well, making more direct contacts among the CNT filler particles leading to dielectric permittivity $\varepsilon^{\prime}$ increase. Additionally, by increasing CNT content, at low frequencies, high dielectric losses caused by conductivity characteristics gradually start to dominate and dielectric permittivity $\varepsilon^{\prime}$ could not be precisely measured due to high dissipation of $\varepsilon^{\prime}$ values.

As opposed to dielectric permittivity, the increase in AC conductivity $\sigma^{\prime}$ by several orders of magnitude was described in our previous work about PET/CNT nanocomposite electrical properties [16], where EPT/CNT nanocomposites with high CNT contents showed conductive behavior and conductivity percolation threshold CNT concentration was calculated at 0.98 wt. \%. The investigation of PET/CNT electrical and thermal conductivity was important for the determination of thermoelectric parameters.

3.4. Rheological Properties. PET/CNT nanocomposites show increase in complex viscosity $\eta^{*}$ (Figure 5), especially at 2 wt. $\%$ and 5 wt. \% CNT concentrations in comparison with the PET matrix which refers to the formation of connected or network structures as a result of CNT-CNT filler and CNTpolymer interactions. Such nanocomposite behavior may also be related to the existence of friction between anisotropic CNTs due to their high $1 / \mathrm{d}$ ratio. Therefore, the nanocomposites showed a pronounced pseudoplastic fluid behavior even at low angular frequency $\omega$ values. Approximation of the viscosity curves of the investigated nanocomposites to the viscosity curve of the polymer matrix at higher $\omega$ values indicates that not only polymer intermolecular bonds collapse and macromolecules deform in the direction of flow but also 


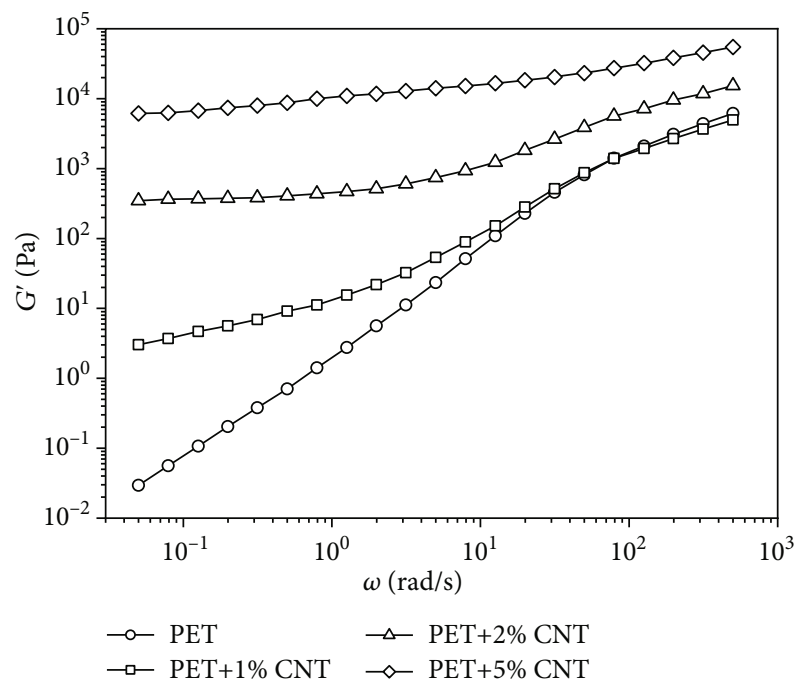

Figure 6: PET/CNT nanocomposite storage modulus $G^{\prime}(\omega)$ curves.

CNT and polymer macromolecule-created structures collapse $[18,19]$.

Dependence of the PET/CNT nanocomposite storage modulus $\left(G^{\prime}\right)$ on $\omega$ (Figure 6 ) shows that the PET matrix possesses the strongest $G^{\prime}$ dependence on $\omega$, while the PET/CNT nanocomposites $G^{\prime}$ dependence on $\omega$ decreased. A gradual decrease of the nanocomposite $G^{\prime}(\omega)$ curve slope by increasing the CNT content can be explained by the fact similar to the change in $\eta^{*}$ when the CNT-CNT or CNTpolymer interactions lead to the formation of connected or network structures resulting in more pronounced pseudoplastic fluid-like behavior [20].

Similarly, as calculating the electrical percolation concentration, in order to calculate the rheological percolation concentration, it is possible to apply the percolation power law based on the variation of $G^{\prime}$ modulus, since the $G^{\prime}$ modulus most clearly describes the rheological changes of nanocomposites depending on the CNT concentration [21]:

$$
G^{\prime} \approx G_{0}^{\prime}\left(\varphi-\varphi_{c, G^{\prime}}\right)^{t_{G^{\prime}}}
$$

where $G^{\prime}$ is the composite storage modulus, $G^{\prime}{ }_{0}$ is the CNT storage modulus, $\varphi$ is the CNT volume content, $\varphi_{c, G^{\prime}}$ is the CNT percolation volume content, and $t_{G^{\prime}}$ is the exponent related to the system dimensionality.

PET/CNT nanocomposite (Figure 7) $\varphi_{c, G^{\prime}}$ values were obtained at 0.64 vol. \% (0.83 wt. \%). Calculated PET/CNT $\varphi_{c, G^{\prime}}$ values are $0.18 \mathrm{wt}$. \% lower than electrical percolation $\varphi_{c, G^{\prime}}$ values as described in our previous work [16]. This is related to different percolation mechanisms with respect to interparticle distance within the composite. For electrical percolation, sufficiently dense CNT network in a polymer matrix is required (at least to ensure electrical charge transfer via tunneling effect), but in the case of rheological percolation, interaction is possible even at larger distances between CNTs (i.e., in the range of radius of gyration of polymer macromolecules). Consequently, $\eta^{*}$ and $G^{\prime}$ increase is deter-

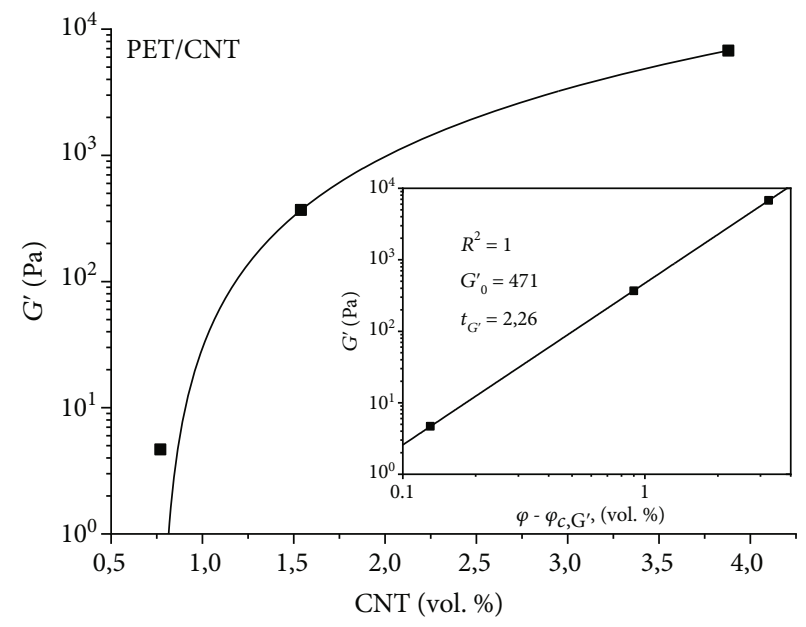

Figure 7: PET/CNT nanocomposite rheological percolation parameters.

mined by the interaction of CNT-polymer in polymer melt, by $\mathrm{CNT}$ interfering with macromolecule movement. The obtained $t_{G^{\prime}}$ values generally depend on the filler $1 / \mathrm{d}$ ratio and angular frequency [22].

\section{Conclusions}

The CNT addition to PET affected dynamic mechanical properties of the investigated nanocomposites by increasing the storage modulus and glass transition temperature by hindering PET macromolecular chain motions. CNTs also acted as nucleating agents in PET by promoting crystallization of the polymer matrix from the melt and consequently influencing mechanical properties. Non-Newtonian melt behavior of the nanocomposites with increase of the nanofiller content in the PET matrix indicates the presence of network structures in the composite, developed at a certain nanofiller content. When the content of nanotubes exceeded 0.83 wt. \%, rheological percolation threshold was observed, respectively. Pronounced interphase polarization between the electrically conductive CNTs and the nonconductive polymer matrix was also observed.

\section{Data Availability}

The figures data and research article that supplements the findings of this study are available from the corresponding author upon request.

\section{Conflicts of Interest}

The authors declare that there is no conflict of interest regarding the publication of this paper.

\section{Acknowledgments}

This research received financial support by ERDF project No. 1.1.1.1/16/A/257. 


\section{References}

[1] Z. Spitalsky, D. Tasis, K. Papagelis, and C. Galiotis, "Carbon nanotube-polymer composites: chemistry, processing, mechanical and electrical properties," Progress in Polymer Science, vol. 35, no. 3, pp. 357-401, 2010.

[2] P.-C. Ma, N. A. Siddiqui, G. Marom, and J.-K. Kim, "Dispersion and functionalization of carbon nanotubes for polymerbased nanocomposites: a review," Composites Part A Applied Science and Manufacturing, vol. 41, no. 10, pp. 1345-1367, 2010.

[3] S. Thomas and P. M. Visakh, Handbook of Engineering and Speciality Thermoplastics: Polyethers and Polyesters, Volume 3, Wiley-Scrivener, 2011.

[4] R. Abbel, Y. Galagan, and P. Groen, "Roll-to-roll fabrication of solution processed electronics," Advanced Engineering Materials, vol. 20, article 1701190, 2018.

[5] B. W. Ahn, Y. S. Chi, and T. J. Kang, "Preparation and characterization of multi-walled carbon nanotube/poly(ethylene terephthalate) nanoweb," Journal of Applied Polymer Science, vol. 110, no. 6, pp. 4055-4063, 2008.

[6] F. Xin, L. Li, S. H. Chan, and J. Zhao, "Influences of carbon fillers on electrical conductivity and crystallinity of polyethylene terephthalate," Journal of Composite Materials, vol. 46, no. 9, pp. 1091-1099, 2011.

[7] S. Yesil and G. Bayram, "Effect of carbon nanotube surface treatment on the morphology, electrical, and mechanical properties of the microfiber-reinforced polyethylene/poly(ethylene terephthalate)/carbon nanotube composites," Journal of Applied Polymer Science, vol. 127, no. 2, pp. 982-991, 2012.

[8] I. Alig, P. Pötschke, D. Lellinger et al., "Establishment, morphology and properties of carbon nanotube networks in polymer melts," Polymer, vol. 53, no. 1, pp. 4-28, 2012.

[9] J. H. Du, J. Bai, and H. M. Cheng, "The present status and key problems of carbon nanotube based polymer composites," Express Polymer Letters, vol. 1, no. 5, pp. 253-273, 2007.

[10] O. Rodríguez-Uicab, A. May-Pat, F. Avilés, P. Toro, and M. Yazdani-Pedram, "Influence of processing method on the mechanical and electrical properties of MWCNT/PET composites," Journal of Materials, vol. 2013, Article ID 656372, 10 pages, 2013.

[11] R. R. Chowreddy, K. Nord-Varhaug, and F. Rapp, "Recycled polyethylene terephthalate/carbon nanotube composites with improved processability and performance," Journal of Materials Science, vol. 53, no. 9, pp. 7017-7029, 2018.

[12] J. Y. Kim, H. S. Park, and S. H. Kim, "Multiwall-carbon-nanotube-reinforced poly(ethylene terephthalate) nanocomposites by melt compounding," Journal of Applied Polymer Science, vol. 103, no. 3, pp. 1450-1457, 2007.

[13] B. A. Alshammari and A. Wilkinson, "Impact of carbon nanotubes addition on electrical, thermal, morphological, and tensile properties of poly (ethylene terephthalate)," Applied Petrochemical Research, vol. 6, no. 3, pp. 257-267, 2016.

[14] E. Logakis, P. Pissis, D. Pospiech et al., "Low electrical percolation threshold in poly(ethylene terephthalate)/multi-walled carbon nanotube nanocomposites," European Polymer Journal, vol. 46, pp. 928-936, 2010.

[15] G. Hu, C. Zhao, S. Zhang, M. Yang, and Z. Wang, "Low percolation thresholds of electrical conductivity and rheology in poly(ethylene terephthalate) through the networks of multi- walled carbon nanotubes," Polymer, vol. 47, no. 1, pp. 480 488, 2006.

[16] J. Bitenieks, R. Merijs Meri, J. Zicans, M. Kalnins, J. Andzane, and K. Buks, "Electrical and mechanical properties of meltprocessed polyethylene terephthalate/multi-wall carbon nanotube nanocomposites for thermoelectric materials," Mechanics of Composite Materials, vol. 54, no. 4, pp. 457-462, 2018.

[17] J.-Y. Kim, T. Y. Kim, J. W. Suk et al., "Enhanced dielectric performance in polymer composite films with carbon nanotubereduced graphene oxide hybrid filler," Small, vol. 10, no. 16, pp. 3405-3411, 2014.

[18] S. H. Jin, Y.-B. Park, and K. H. Yoon, "Rheological and mechanical properties of surface modified multi-walled carbon nanotube-filled PET composite," Composites Science and Technology, vol. 67, no. 15-16, pp. 3434-3441, 2007.

[19] Y. Pan and L. Li, "Percolation and gel-like behavior of multiwalled carbon nanotube/polypropylene composites influenced by nanotube aspect ratio," Polymer, vol. 54, no. 3, pp. 12181226, 2013.

[20] P. Verma, M. Verma, A. Gupta, S. S. Chauhan, R. S. Malik, and V. Choudhary, "Multi walled carbon nanotubes induced viscoelastic response of polypropylene copolymer nanocomposites: effect of filler loading on rheological percolation," Polymer Testing, vol. 55, pp. 1-9, 2016.

[21] C. Penu, G.-H. Hu, A. Fernandez, P. Marchal, and L. Choplin, "Rheological and electrical percolation thresholds of carbon nanotube/polymer nanocomposites," Polymer Engineering and Science, vol. 52, no. 10, pp. 2173-2181, 2012.

[22] F. Du, R. C. Scogna, W. Zhou, S. Brand, J. E. Fischer, and K. I. Winey, "Nanotube networks in polymer nanocomposites: rheology and electrical conductivity," Macromolecules, vol. 37, no. 24 , pp. 9048-9055, 2004. 